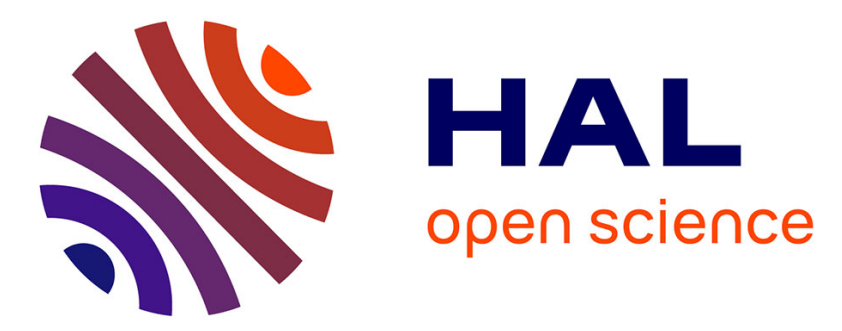

\title{
Electromagnetic Wave Reflection from Shocked Dielectric Materials
}

Benoit Rougier, Hervé Aubert, Alexandre Lefrançois

\section{To cite this version:}

Benoit Rougier, Hervé Aubert, Alexandre Lefrançois. Electromagnetic Wave Reflection from Shocked Dielectric Materials. IEEE Antennas and Propagation Symposium, Jul 2018, Boston, United States. 3p., 10.1109/APUSNCURSINRSM.2018.8608420 . hal-01876698

\section{HAL Id: hal-01876698 \\ https://hal.laas.fr/hal-01876698}

Submitted on 18 Sep 2018

HAL is a multi-disciplinary open access archive for the deposit and dissemination of scientific research documents, whether they are published or not. The documents may come from teaching and research institutions in France or abroad, or from public or private research centers.
L'archive ouverte pluridisciplinaire $\mathbf{H A L}$, est destinée au dépôt et à la diffusion de documents scientifiques de niveau recherche, publiés ou non, émanant des établissements d'enseignement et de recherche français ou étrangers, des laboratoires publics ou privés. 


\title{
Electromagnetic Wave Reflection from Shocked Dielectric Materials
}

\author{
B. Rougier ${ }^{1,2, \mathrm{c}}, \mathrm{H}$. Aubert ${ }^{1}$, \\ ${ }^{1}$ LAAS-CNRS \\ Toulouse, France \\ c :brougier@laas.fr
}

\author{
A. Lefrançois ${ }^{2}$ \\ ${ }^{2}$ CEA Gramat \\ Gramat, France
}

\begin{abstract}
In this paper, an analytical model is proposed for computing the time-harmonic electromagnetic wave reflected by shocked dielectric materials. This model finds application in the remote sensing of shock waves in dielectric materials. First results obtained from shocked PolyMethyl MethAcrilate are reported and discussed.
\end{abstract}

Keywords-Electromagnetic field theory, shock waves in solids, remote sensing, moving dielectric interfaces.

\section{INTRODUCTION}

Microwave interferometers were recently used for measuring shock-wave velocity in solids subjected to steady shocks [1] but, to the authors' knowledge, were not yet applied to unsteady shocks in solid dielectrics. When a shock wave propagates in dielectrics, multiple semi-transparent dielectric interfaces moving at different velocities are generated behind the shock-wave front. We propose here to use millimeterwave interferometers for remotely deriving (1) the velocities of these interfaces and (2) the dielectric permittivity profile behind the shock-wave front. An analytical model is proposed for determining the electromagnetic wave reflected by multiple dielectric interfaces moving at different constant velocities. Next, this model is applied to the computation of a $94 \mathrm{GHz}$ time-harmonic electromagnetic field reflected by a shocked PolyMethyl MethAcrilate material. First numerical results are reported and discussed.

\section{THEORY}

We consider here a stratified dielectric material with $I$ moving interfaces. The $I$-th interface is a perfectly conducting plate while the other interfaces $(i=1,2,3, \ldots, I-1)$ are lossless dielectric planar surfaces (see Figure 1$)$. The $i$-th interface has a constant velocity denoted by $V_{i}$. A linearly-polarized transverse time-harmonic electric field $\vec{E}_{i n c}(z, t)=\vec{E} e^{j \omega t-j k_{1} z}$ is normally incident upon first interface ( $i=1$ ) where $E$ is the field amplitude, $\omega$ denotes the radial operating frequency of the incident electromagnetic field and $k_{1}$ designates the wavenumber of this field. At each interface $i(i=1,2 \ldots I-1)$, the electromagnetic field is reflected and transmitted. At each time step $t_{n}$, the stratified material is modeled as a multilayered structure composed of $I-1$ stacked dielectric layers. Assuming small interface velocities compared with the velocity $c$ of the light in vacuum, the thickness of the $j$-th layer $(j=2, \ldots, I)$ is derived from the time step $t_{n}$ and the velocity difference $\left(V_{j-1}-V_{j}\right)$.

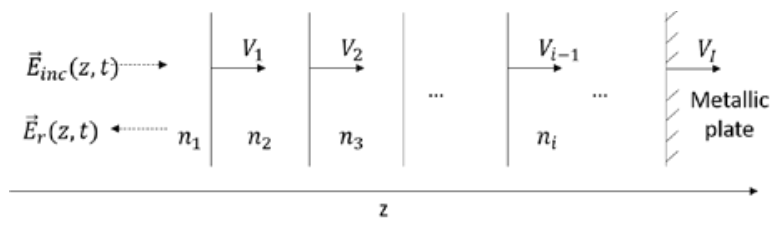

Figure 1: The figure displays the multiple dielectric interfaces generated behind the shock-wave front when a dielectric material are subjected to unsteady shocks. All interfaces move at constant velocities and the refractive index between two successive interfaces is assumed to be uniform.

The total reflected electric field at time step $t_{n}$ is then computed from multiple reflections and transmissions inside the stratified material built at this time step. The reflection coefficient $R_{I, I+1}$ at the perfectly conducting interface $i=I$ equals to -1 while, for $i=1$, 2, 3..., I-1, the reflection and transmission coefficients $R_{i, i+1}$ and $T_{i, i+1}$ are given by :

$$
R_{i, i+1}=\frac{n_{i+1}-n_{i}}{n_{i+1}+n_{i}} \quad \text { and } \quad T_{i, i+1}=\frac{2 n_{i}}{n_{i+1}+n_{i}}
$$

where $n_{i}$ designates the uniform refractive index between the interface $i$ and interface $i+1$. Due to the Doppler effect generated at each moving interface, the radial frequency $\omega_{r}^{(i)}$ in Eq.(1) differs from the radial frequency $\omega$ of the incident electromagnetic field and according to [2], it can be approximated by the following relationship: 


$$
\omega_{r}^{(i)}=\omega_{1} D_{R i, i+1} \prod_{p=1}^{i-1} D_{T p, p+1} D_{T p+1, p}
$$

where

$D_{R i, i+1} \approx 1-2 n_{i} \frac{V_{i}}{c}$ and $D_{T_{i, i+1}} \approx 1-n_{i} \frac{V_{i}}{c}-n_{j} \frac{V_{i+1}-V_{i}}{c}$

\section{APPLICATION}

As a first application, we consider here the impact of an iron cylinder (thickness of $1 \mathrm{~mm}$ and diameter of $30 \mathrm{~mm}$ ) on a cylindrical PolyMethyl MethAcrilate (PMMA) material (thickness of $25 \mathrm{~mm}$ and diameter of $30 \mathrm{~mm}$ ). The velocity of the iron impactor is of $550 \mathrm{~m} / \mathrm{s}$. The impact (at time $t_{1}=0 \mathrm{~s}$ ) generates a shock-wave in the PMMA material. This wave creates multiple semi-transparent dielectric interfaces moving at different velocities in the shocked material and it modifies its refractive index behind the wavefront [3]. The resulting spatial and time variation of the refractive index as well as the interface velocities are computed here at each time step by using an in-house 1D hydrodynamic simulation software. Every $500 n s\left(=t_{n+1}-t_{n}\right)$ after the impact, the refractive index profile as well as the profile of interface velocity are then computed. For illustration purpose, Figure 2 displays these profiles at time $t_{4}=2 \mu \mathrm{s}$ after the impact. From the computed profiles, we model the PMMA material at each time step as a multilayered structure composed of 2500 stacked dielectric layers of thickness of $\lambda / 320$, where $\lambda(=3.2 \mathrm{~mm})$ is the wavelength of the $94 \mathrm{GHz}$ incident electromagnetic field.
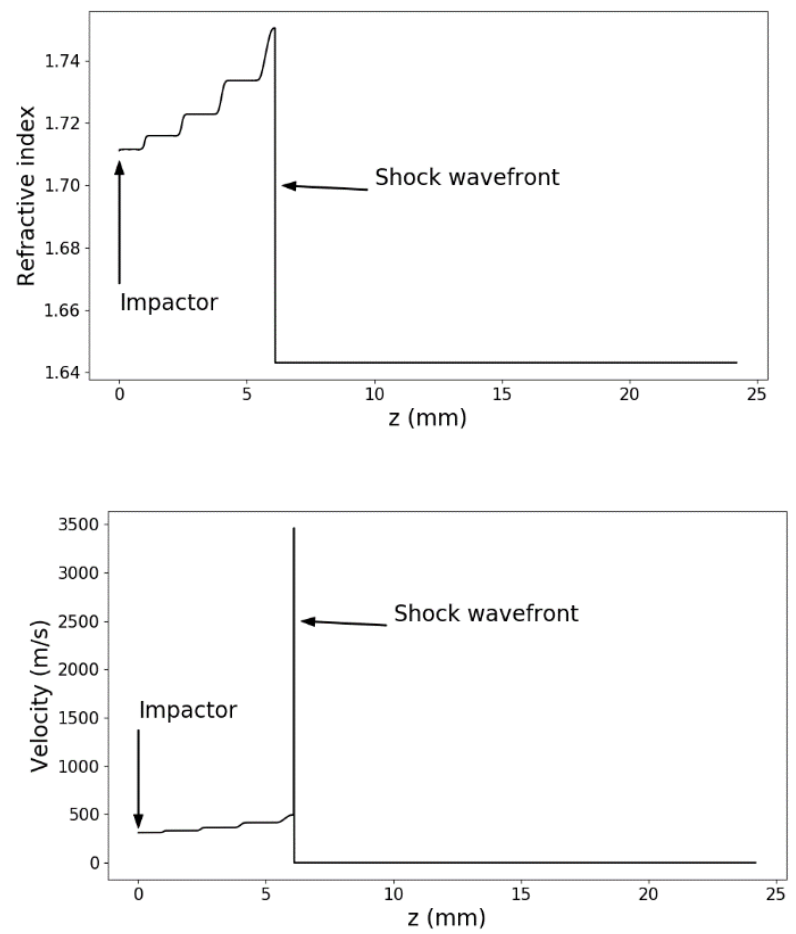

(a)

(b)

Figure 2: Profiles derived from a 1D hydrocode simulation software of: (a) the refractive index and (b) the velocity of dielectric interfaces. These profiles are generated behind the shock wavefront in the PMMA material $2 \mu$ s after an impact occurring at $z=0$ (velocity of the iron impactor : $550 \mathrm{~m} / \mathrm{s}$ )

Next, for $i=1,2, \ldots, I$ and at each time step, we derive the normalized component the radial frequency $\omega_{r}^{(i)}$ from Eq.(2) and the spectral component associated with this frequency. Figure 3 displays these components and the corresponding frequencies $f_{r}^{(i)}=$ $\omega_{r}^{(i)} / 2 \pi$ for 11 time steps ranging from 0 (time of the impact) to $5.5 \mu \mathrm{s}$. We observe that the component associated with the first interface ( $i=1)$ has a magnitude significantly higher than other component amplitudes. In addition to this dominant contribution to 
the reflected field, we observe from Figure 3 that a second strong contribution occurs at frequency $f_{r}^{I}$. This contribution corresponds to the direct reflection of the incident electromagnetic field by the surface of the metallic impactor (interface $I$ ).

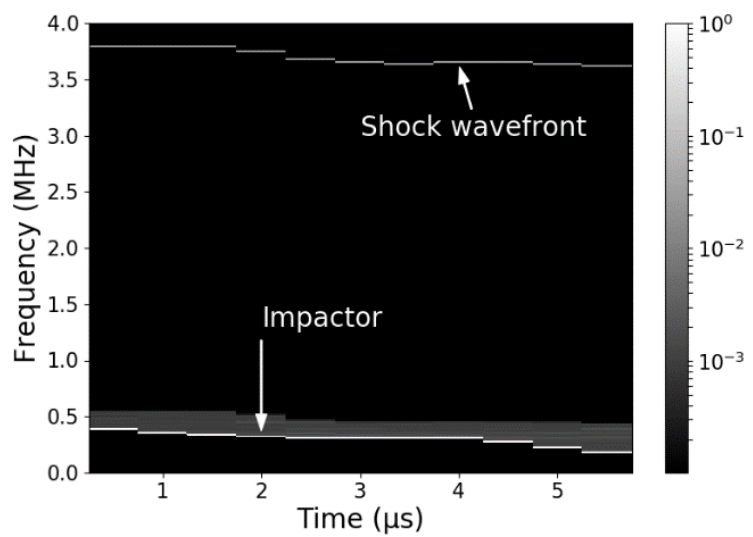

Figure 3: The spectral component associated with frequency $f_{r}^{(i)}$ (see Eq. (2)) as a function of time step $t_{n}$ and $f_{r}^{(i)}$.

We conclude that the total reflected field is the result of two major contributions: (1) the contribution of the direct reflection on the metallic surface of the impactor, and (2) the contribution of the reflection on the shock wavefront. The frequency associated with the latter ranges from $3.8 \mathrm{MHz}$ (at $t_{1}=0 \mathrm{~s}$ ) to $3.58 \mathrm{MHz}$ (at $t_{11}=5.5 \mu \mathrm{s}$ ), while the frequency associated with the former is between $140 \mathrm{kHz}$ and $393 \mathrm{kHz}$.

\section{CONCLUSION}

An analytical model is proposed for computing the electromagnetic wave reflected by multiple dielectric interfaces moving at different velocities. We report and discussed a first application on the millimeter-wave electromagnetic field reflected by a PMMA material subjected to an impact. This model contributes to pave the road to the millimeter-wave remote sensing of shock waves in dielectric materials.

\section{REFERENCES}

[1] V.M. Bel'skii, A.L. Mikhailov, A.V. Rodionov and A.A. Sedov, "Microwave diagnostics of shock-wave and detonation process", Comb, Expl, Shock Waves, vol. 47, pp. 639-650, 2011.

[2] W.P. Birkemeier, H.S. Merrill Jr, D.H. Sargeant, D.W. Thomson, C.M. Beamer and G.T. Bergemann, "Observation of wind-produced Doppler shifts in tropospheric scatter propagation”, 1968, Rad. Sci., vol. 3, pp. 309-317.

[3] D.J. Chapman, D.E. Eakins, D.M. Williamson and W.G. Proud, "Index of refraction measurements and window corrections for PMMA under shock compression”, AIP Conf. Proc., vol. 1426, pp. 442-445, 2012. 